\title{
RAPID ULTRASOUND ASSISTED REDUCTION OF AZO DYES FOR SCREENING BANNED AROMATIC AMINES
}

\section{RAJKUMAR DEWANI MUHAMMAD KASHIF PERVEZ ${ }^{a}$, MUHAMMAD FAROOQ WAHAB ${ }^{d}$, TAHIRA AYAZ ${ }^{\mathrm{a}}$}

\begin{abstract}
The screening of harmful colorants in consumer products is a global concern. Majority of textile and leather exports undergo extensive quality testing, consuming a lot of time and energy. Consequently, improvements in the rate of reduction of standard method for harmful azo dyes, EN 14362-1:2012 (Annex. F), by combining conventional heating with ultrasonication have been explored to adopt a greener approach. Basic dye behavior was investigated by UV-visible spectroscopy, so that more efficient reduction methods could be designed for high-tech instruments of analysis like HPLC with diode array detection (DAD) and GC with mass spectrophotometer (GC-MS). Four dyes were selected, namely Acid red 1 (AR-1), Direct blue 15 (DB-15), Direct red 28 (DR-28), and Direct red 7 (DR7) containing one harmful aromatic amine in their structures which make them critical for analyses. Basic observation that absorbance of dyes (having azo chromospheres in their structure) decreases with their reduction to amines was exploited using UV-visible spectroscopic analysis with preselected absorption bands in the visible region from 400 to $700 \mathrm{~nm}$. The dyes were subjected to two types of ultrasound assisted reduction (UAR) methods; less vigorous (experimental method 1) and more vigorous (experimental method 2). All dyes achieved reductions through ultrasonic assistance, higher than the reference method within ten min of time at or before $70^{\circ} \mathrm{C}$ except DR-28, according to experimental method 1. According to experimental method 2, DB-15 and DR-7 achieved reductions equivalent to the reference method in $15 \mathrm{~min}$ of UAR at $70{ }^{\circ} \mathrm{C}$ whereas AR-1 and DR28 achieved in $20 \mathrm{~min}$ of UAR. Finally, DR-28 was further subjected to experimental method 3, which was simply EN 14362-1:2012 (F) method for
\end{abstract}

a Leather Research Center, PCSIR, D/102, South Avenue, S.I.T.E, Karachi, Pakistan

b Dept. of Chemistry, University of Karachi, University Road, Karachi-75270, Pakistan

* Corresponding author: rajdewaan@gmail.com

c Centre of Excellence in Marine Biology, University of Karachi, University Road, Karachi75270, Pakistan

d Dept. of Chemistry \& Biochemistry, University of Texas at Arlington, TX, USA 
colorants, with UAR. At this stage, standard techniques of analysis exploiting HPLC-DAD and GC-MS were used. According to experimental method 3, even 15 min of UAR caused a greater reduction of DR-28 dye as compared to the standard method (BS EN $14362-1, \mathrm{~F}$ ). Ultrasonication at $70^{\circ} \mathrm{C}$ reduced the total dye reduction time by $42 \%$ and energy consumption by $85 \%$.

Keywords: Azo dyes, Green chemistry, Ultrasound assisted reduction (UAR), Banned aromatic amines

\section{INTRODUCTION}

Colors enhance the beauty and diversity in our lives. The major part of colorants (dyes and pigments) in human use is synthetic, having several chromophores and auxochromes in their structures. Majority of chromophores are azo. Unfortunately, sometimes there are serious issues associated with dyes having azo bonds in their structures. In some cases, the azo chromophore may undergo reductive cleavage, releasing mutagenic or carcinogenic aromatic amines into the environment. These aromatic amines create acute and chronic diseases in humans [1, 2], other terrestrial [3-7] and aquatic living organisms [8, 9]. Azo bond stability and the type of aromatic amines present in a dye play a decisive part in the acceptance of a dyed product. There are 22 aromatic amines ( 24 in case of leather) banned by the EU, USA, and many other countries [10]. Standard test methods are available to check the release of harmful aromatic amines from colorants [11], dyed leather [12] and textile products [13]. Standard test methods are based on three sequential steps; (i) controlled reduction, (ii) solid phase extraction, and finally (iii) identification and determination. The reduction step consumes around $1 \mathrm{~h}$ and is critical for the test.

A number of methods were used for the reduction of azo dyes using; $25 \%$ sodium dithionite [14], sodium dithionite in boiling water [15], in water, methanol mixture, $25 \%$ [16], and $40 \%$ [17] tin chloride solutions. Similarly, extraction of aromatic amines has been reported through liquid-liquid extraction with 1,1,1-trichloroethane [16], with chloroform [15, 18], ethyl acetate [14, 17], and diethyl-ether [19]. The extracted aromatic amines were analyzed through TLC and IR spectroscopy $[15,16]$, HPLC with UV detection [19], with DAD [20], HPLC-MS [14, 17] and GC-MS [17, 18]. Most common techniques reported for aromatic amines are GC-MS and HPLC-DAD, but some studies prefer the later over the former [21]. 
In recent years reactions and processes are being transformed on the principles of green chemistry to be safe for the environment. Among other techniques used in green chemistry, microwave heating and ultrasonication find vast applications for improving the efficiency of different reactions and extractions [22-26]. Ultrasonication causes cavitations in the liquid medium due to acoustic energy, forming bubbles that implode to dissipate the energy by raising local temperatures and pressures [27]. Two types of ultrasound frequencies are generally utilized for chemical reactions, power ultrasound (20 to $100 \mathrm{kHz}$ ) and sonochemical ultrasound (300 to $1000 \mathrm{kHz}$ ).

Several studies on degradation of dyes have been reported through ultrasonication alone [23-25]. Ultrasonic degradation of basic azo and anthraquinone dyes at $300 \mathrm{kHz}$ were reported in exhausted dye baths at acidic and near acidic $\mathrm{pH}$ [23]. Similarly, four textile dyes were degraded in water by $520 \mathrm{kHz}$ of ultrasonic energy [24]. Likewise, two mono azo dyes, acid orange 7 and acid orange 8 were sonochemically degraded from their tautomeric forms in solution at $300 \mathrm{kHz}$ [28]. Ultrasonic energy has been coupled with biodegradation [29-33], catalytic degradation [34], and with other processes [35-39] for dye cleavage.

It has been established that the degradation of dyes is influenced by their azo chromophores. Hydroxyl radicals generated in the ultrasonication of water in the sonochemical range attack the azo bonds preferably, resulting in color disappearance [24]. Ultrasonication favors dye degradation by protonating the molecule more effectively at acidic media $(\mathrm{pH}=6.0)$, making it slightly hydrophobic and more prone to the negatively charged cavity bubbles created and destroyed during ultrasonication [40].

The current study presents the reductive degradation of an acid and three direct dyes containing mono and bisazo chromophores, respectively, exploiting UV-Visible spectroscopy.

Four dyes (Figure 1), AR-1, DB-15, DR-28, and DR-7 were chosen due to the presence of at least one harmful amine in their structure, their water solubility, vast applications on leather and textile, and availability in local market. Several methods incorporating mild to vigorous reduction techniques have been reported for the analyses of azo dyes individually as well as in dyed matrices [41]. Internationally recognized standard method for the analyses of certain aromatic amines derived from azo colorants is BS EN 14362-1 (annex. F) [11].

The reduction procedure in the standard method utilizes sodium dithionite at $70^{\circ} \mathrm{C}$ for $30 \mathrm{~min}$ in a pre-heated citrate buffer adjusted to $\mathrm{pH}$ 6.0. In this study, the standard method of analyzing harmful aromatic amines in azo colorants has been modified by the incorporation of heated ultrasonication as an alternative greener approach for dye reduction. 


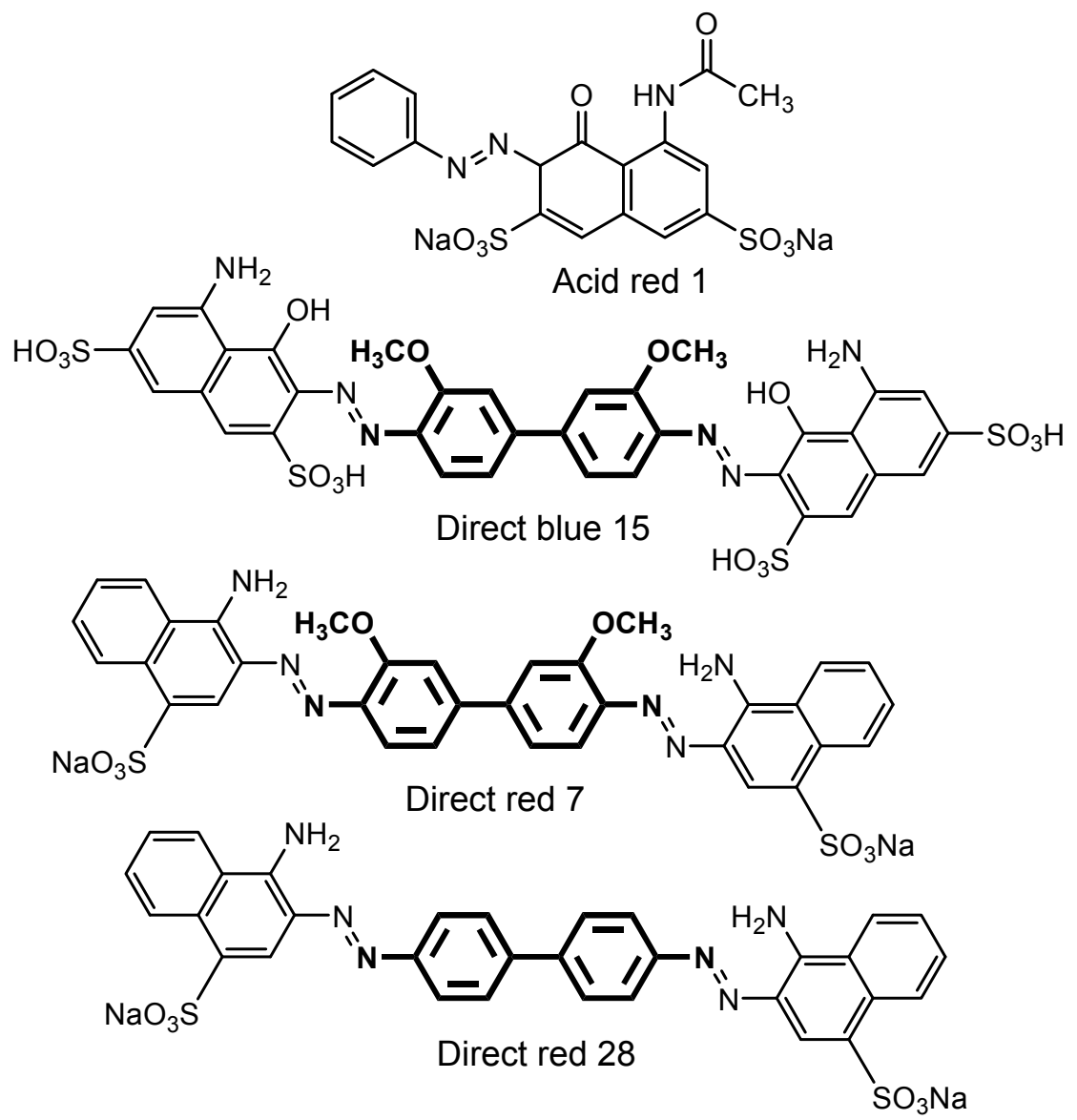

Figure 1. Dye structures with banned aromatic amine component in bold

\section{RESULTS AND DISCUSSION}

The change in UV and visible absorptions in different azo (direct and acid) dyes upon reduction by sodium dithionite, helped to monitor (a) the effects of changing temperature on UAR and (b) effects of changing UAR time at fixed temperature. 


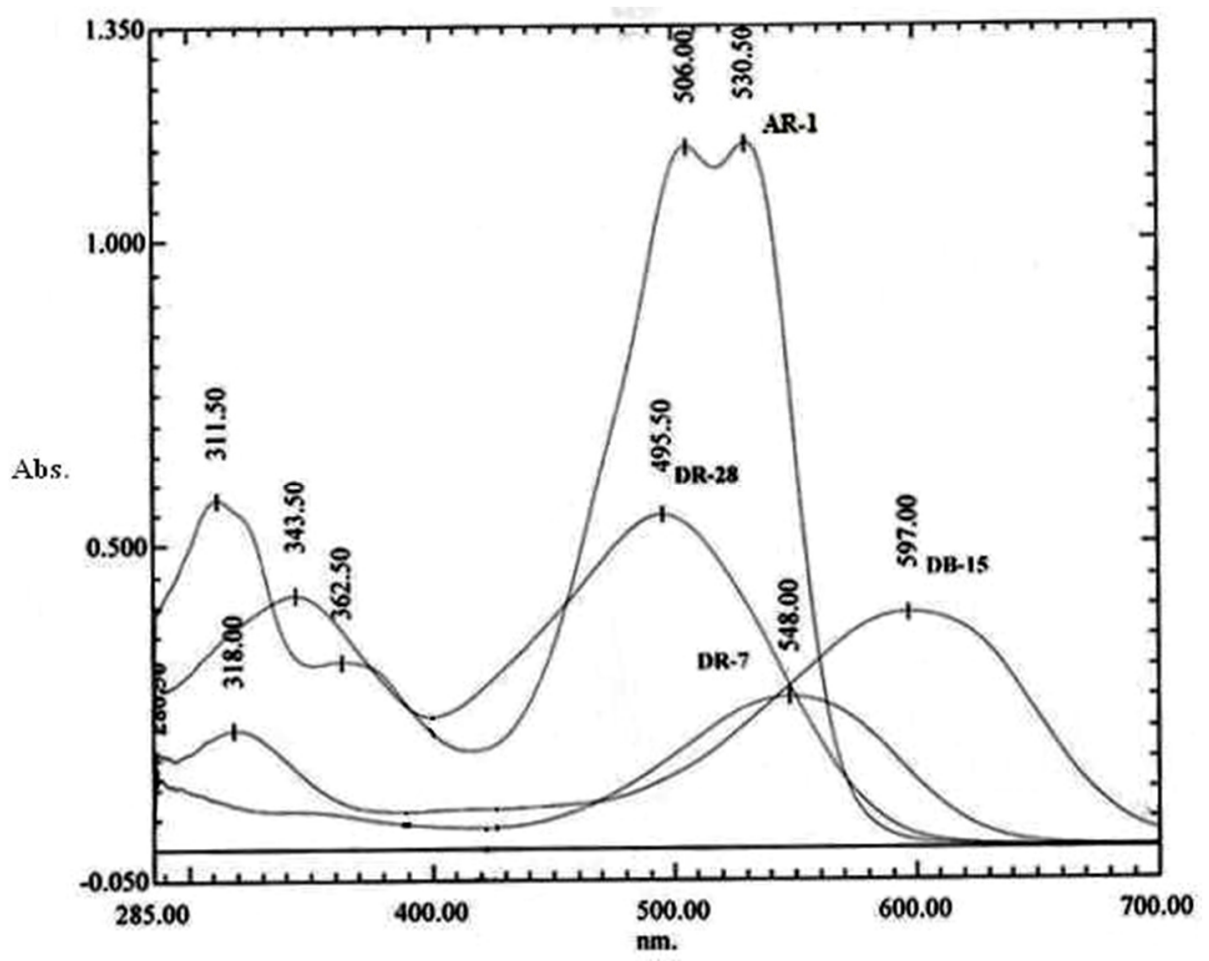

Figure 2. UV-Visible scans of Direct red 28, Acid red 1, Direct red 7 and Direct blue 15 dyes (with peaks marked)

UV-visible scans of the dyes; DB-15, AR-1, DR-7, and DR-28 were recorded in water (Figure 2).

The frequency range from 300 to $1000 \mathrm{kHz}$, recommended for chemical modifications, is referred to as sonochemical effects ultrasound whereas frequency range from 20 to $100 \mathrm{kHz}$, mostly used for cleaning and degassing purposes, is called power ultrasound [40]. Power ultrasound is employed in the reduction as a supportive aid to sodium dithionite [37, 40]. Sonochemical effects ultrasound could cause some additional reactions [42]. The study is focused on the cleavage of the azo bond using power ultrasound $(40 \mathrm{kHz})$.

Selected wavelengths for each dye are presented in Table 1. In case of DR-28 dye, absorbance changes were prominent, hence only one wavelength was used in experimental method 1. 
Table 1. Selected wavelengths for dyes analyses and associated information

\begin{tabular}{|c|c|c|c|c|}
\hline \multirow{2}{*}{ Dyes } & \multirow{2}{*}{$\begin{array}{c}\text { C. I. } \\
\text { number }\end{array}$} & \multirow{2}{*}{$\begin{array}{c}\text { Mol. wt. } \\
\text { (g/mol) }\end{array}$} & \multicolumn{2}{|c|}{ Wavelengths ' $\boldsymbol{\lambda}$ ' used (nm) } \\
\cline { 4 - 5 } & & & Experimental method 1 & Experimental method 2 \\
\hline AR-1 & 118050 & 509.42 & 506,530 & 506,530 \\
\hline DB-15 & 24400 & 992.80 & 580,608 & $580,594,608$ \\
\hline DR-7 & 24100 & 756.72 & 547,570 & 544,547 \\
\hline DR-28 & 22120 & 696.66 & 505 & 488,505 \\
\hline
\end{tabular}

The reduction reactions have been carried out at low dye concentrations to enable direct absorbance measurements. UV-visible scans of buffer and dithionite solutions were also recorded to check for possible interferences (if any) and they showed maximum absorbance in the far and middle UV regions $(200-330 \mathrm{~nm})$. Absorbance in the visible region was negligible. The upper limit on dye concentration was set roughly to 19 times less than that in the reference methods. Concentration of sodium dithionite is 5 times less than in the reference method for three reasons; (a) it is taken in excess (b) it does not absorb significantly in the visible region and (c) the reduction mechanism is likely to be altered when the concentration of sodium dithionite is reduced below a critical level. Sodium dithionite generates sulfur dioxide radical anions according to the following reaction [43]:

$$
\mathrm{S}_{2} \mathrm{O}_{4}^{2-} \rightleftarrows 2 \mathrm{SO}_{2}^{--}
$$

Both these species are responsible for the reducing property, but dithionite is comparatively a weaker reducing agent.

It is ascertained that the concentration of sulphur dioxide radical anion is inversely proportional to dithionite concentration and vice versa [44]. The concentration of all components of the reaction mixtures were adjusted appropriately in each experimental method and the reactions were conducted using these concentrations (Table 2). Concentrations of dyes, however, were different for the two experimental methods. In experimental method 1 , each dye was reduced at $40,50,60$, and $70^{\circ} \mathrm{C}$ respectively, for 10 min with ultrasound assistance. The degree of reduction was monitored by the change in absorbance. The standard method reduction was similar to experimental method 3 but without ultrasound exposure, having reduction duration of $30 \mathrm{~min}$. The idea behind the research design was to find out greener reaction conditions that could make the test method environmental friendly [45]. 
RAPID ULTRASOUND ASSISTED REDUCTION OF AZO DYES FOR SCREENING BANNED ...

Table 2. Comparison of reduction methods used for dye analysis

\begin{tabular}{|l|c|c|c|c|}
\hline Experimental parameter & $\begin{array}{c}\text { Reference } \\
\text { method }\end{array}$ & $\begin{array}{c}\text { Experimental } \\
\text { method 1 }\end{array}$ & $\begin{array}{c}\text { Experimental } \\
\text { method 2 }\end{array}$ & $\begin{array}{c}\text { Experimental } \\
\text { method 3 }\end{array}$ \\
\hline $\begin{array}{l}\text { Dye concentration range } \\
(\mathrm{mg} / 100 \mathrm{ml})\end{array}$ & $\begin{array}{c}\text { Same as expe } \\
\text { rimental method } \\
1 \text { and 2 }\end{array}$ & $2.2-4.2$ & $3.2-7.8$ & $\begin{array}{c}588-1000 \\
\text { (approx.) }\end{array}$ \\
\hline Dyes analyzed & $\begin{array}{c}\text { DR-7, AR-1, } \\
\text { DB-15 and DR- } \\
28\end{array}$ & $\begin{array}{c}\text { DR-7, AR-1, } \\
\text { DB-15 and } \\
\text { DR-28 }\end{array}$ & $\begin{array}{c}\text { DR-7, AR-1, } \\
\text { DB-15 and } \\
\text { DR-28 }\end{array}$ & DR-28 \\
\hline Buffer strength $(\mathrm{M})$ & 0.03 & 0.03 & 0.03 & 0.06 \\
\hline Preheat time $(\mathrm{min})$ & 30 & - & 20 & 20 \\
\hline Preheat temperature $\left({ }^{\circ} \mathrm{C}\right)$ & 70 & - & 70 & 70 \\
\hline Dithionite strength $(\mathrm{g} / 3 \mathrm{ml})$ & 0.12 & 0.12 & 0.12 & 0.60 \\
\hline Reduction time $(\mathrm{min})$ & 30 & 10 & 10 or 15 & 15 or 20 \\
\hline Reduction temperature $\left({ }^{\circ} \mathrm{C}\right)$ & 70 & $50,60,70$ & 70 & 70 \\
\hline Reaction vessel & Glass RB & Glass RB & PTFE & PTFE \\
\hline Ultrasound exposure & - & $40 \mathrm{KHz}$ & $40 \mathrm{KHz}$ & $40 \mathrm{KHz}$ \\
\hline
\end{tabular}

\section{Effect of temperature on the reduction of dyes applying fixed Ultrasonication (Experimental method 1)}

The results of experimental method 1 are presented in Figure 3 . Comparing the trend in case of AR-1 absorbance decreases initially from 30 to $60^{\circ} \mathrm{C}$.

After $\sim 60^{\circ} \mathrm{C}$ the absorbance starts increasing in the visible region with the formation of pale yellow colored intermediates, disodium 5-(acetylamino)-3amino-4-hydroxy-3,4-dihydronaphthalene-2,7-disulfonate and aniline. Both aromatic amines were generated because of cleavage of the azo bond present in AR-1. The yellow color was predominant when the dye was reduced completely with acidic tin chloride solution $[14,17]$. The reduction profile of DB15 is an almost linear decrease in absorbance with respect to increasing temperature at both 580 and $608 \mathrm{~nm}$. The reduction of DR-7, under the reaction conditions of experimental method 1 showed no noticeable change. A marked degradation was observed when DR-28 was subjected to UAR. A general decrease in absorbance at $505 \mathrm{~nm}$ can be noticed.

Figure 4 gives a comparative account of percent dye reduction of reference method and experimental method 1 , at selected wavelengths. 
R. DEWANI, F. AHMED, M. RASHEED, M. K. PERVEZ, M. F. WAHAB, T. AYAZ

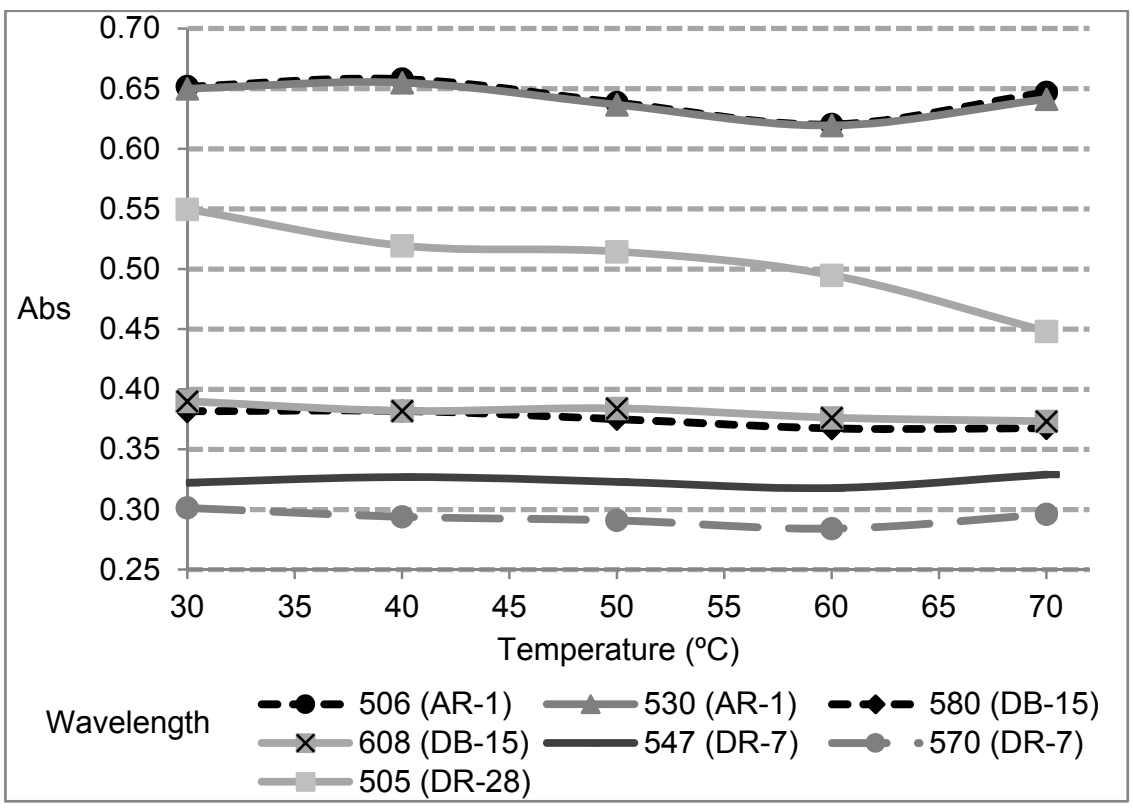

Figure 3. Effect of reaction temperatures on UAR of dyes (Experimental method 1)

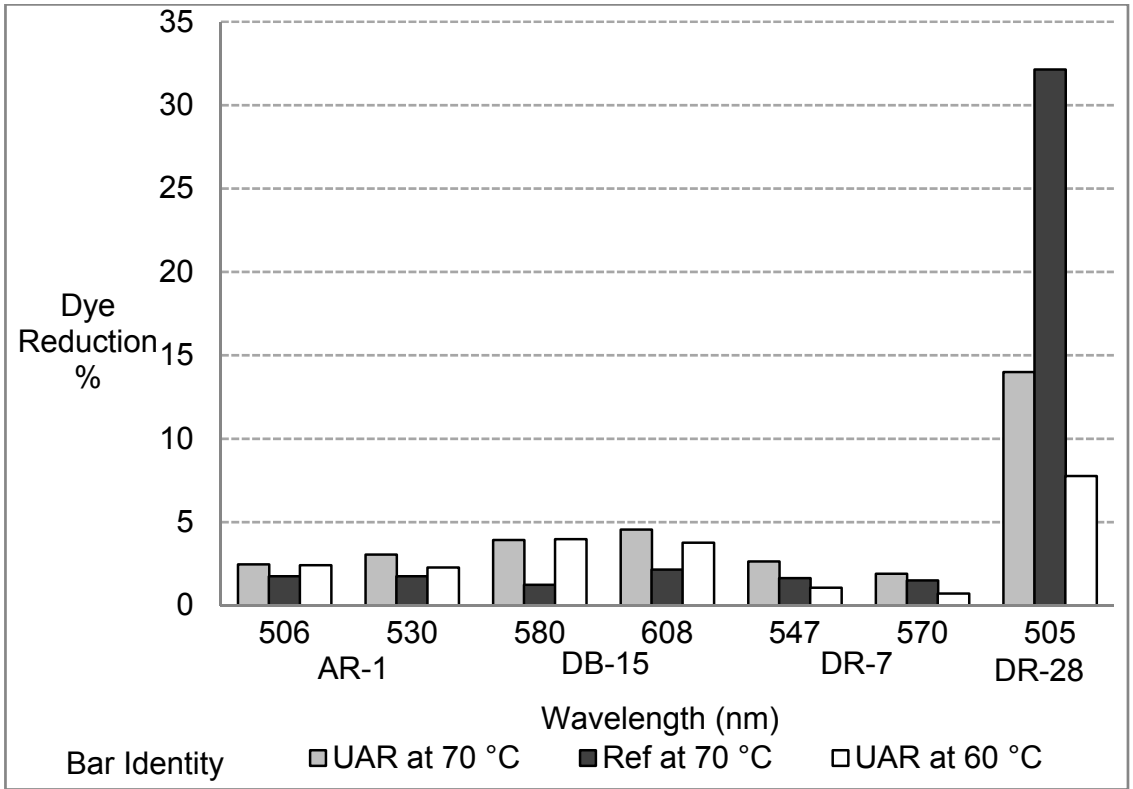

Figure 4. Comparative absorbance difference at selected wavelengths after dyes reduction at $70{ }^{\circ} \mathrm{C}$ between experimental method 1 and reference method 
In AR-1, at $506 \mathrm{~nm}$ the $\mathrm{UAR}$ at 70 and $60^{\circ} \mathrm{C}$ resulted in a slightly greater reduction as compared to the reference method. Similarly, at $530 \mathrm{~nm}$, the reduction results at both 70 and $60^{\circ} \mathrm{C}$ are better than the reference method but the former are slightly better than the later. Similarly, in case of DB-15 the results from ten min of UAR in the visible region (580 and $608 \mathrm{~nm}$ ) at 60 and $70^{\circ} \mathrm{C}$ are better than those obtained by reference method carried out for half an hour at $70{ }^{\circ} \mathrm{C}$. Again, the UAR at $70^{\circ} \mathrm{C}$ is greater than $60{ }^{\circ} \mathrm{C}$ at $608 \mathrm{~nm}$. DR-7 is the most stable among the selected dyes and is hardly affected in the given experimental conditions as reflected in the Figure 3 . However, the results at 547 and $570 \mathrm{~nm}$ suggest that the order of dye reduction is UAR at $70^{\circ} \mathrm{C}>$ reference method $>$ UAR at $60^{\circ} \mathrm{C}$. On the other hand, DR-28 disintegrates to the greatest extent among the selected dyes. However, it is also evident from Figure 4 that 10 min of ultrasound assisted heating at $70^{\circ} \mathrm{C}$ and below is not enough to cause a reduction equivalent to the reference reduction method. To conclude, the exposure of ultrasound waves for $10 \mathrm{~min}$ at $70^{\circ} \mathrm{C}$ caused enhanced reductive degradation in all the four dyes with results parallel to the reference method (30 min) except DR-28.

\section{Effect of exposure of ultrasonication on the reduction of dyes at fixed temperature (Experimental method 2)}

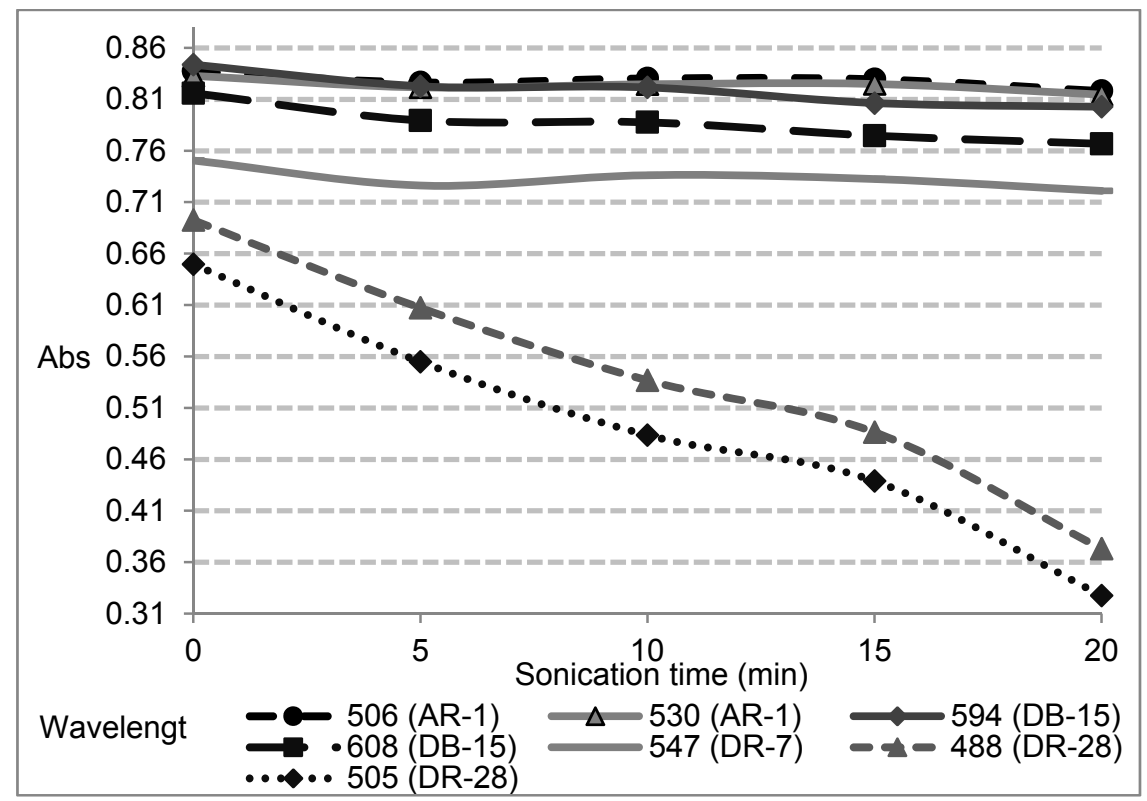

Figure 5. Effect of UAR time on dye degradation (Experimental method 2) 
Considering the results of experimental method 1 , the parameters were modified and experimental method 2 was carried out at $70{ }^{\circ} \mathrm{C}$, exposing the samples with ultrasound for different durations. Reaction temperature was maintained at $70{ }^{\circ} \mathrm{C}$ in analogy to the standard method [11]. Dye concentrations were increased, and the wavelengths were slightly modified to optimize the monitoring of absorbance change (Table 2). Figure 5 gives the reduction profile of the four dyes at conditions stated in experimental method 2.

Figure 6 depicts the potential of UAR, presenting the results of experimental method 2 at 15 and $20 \mathrm{~min}$ in comparison to reference method.

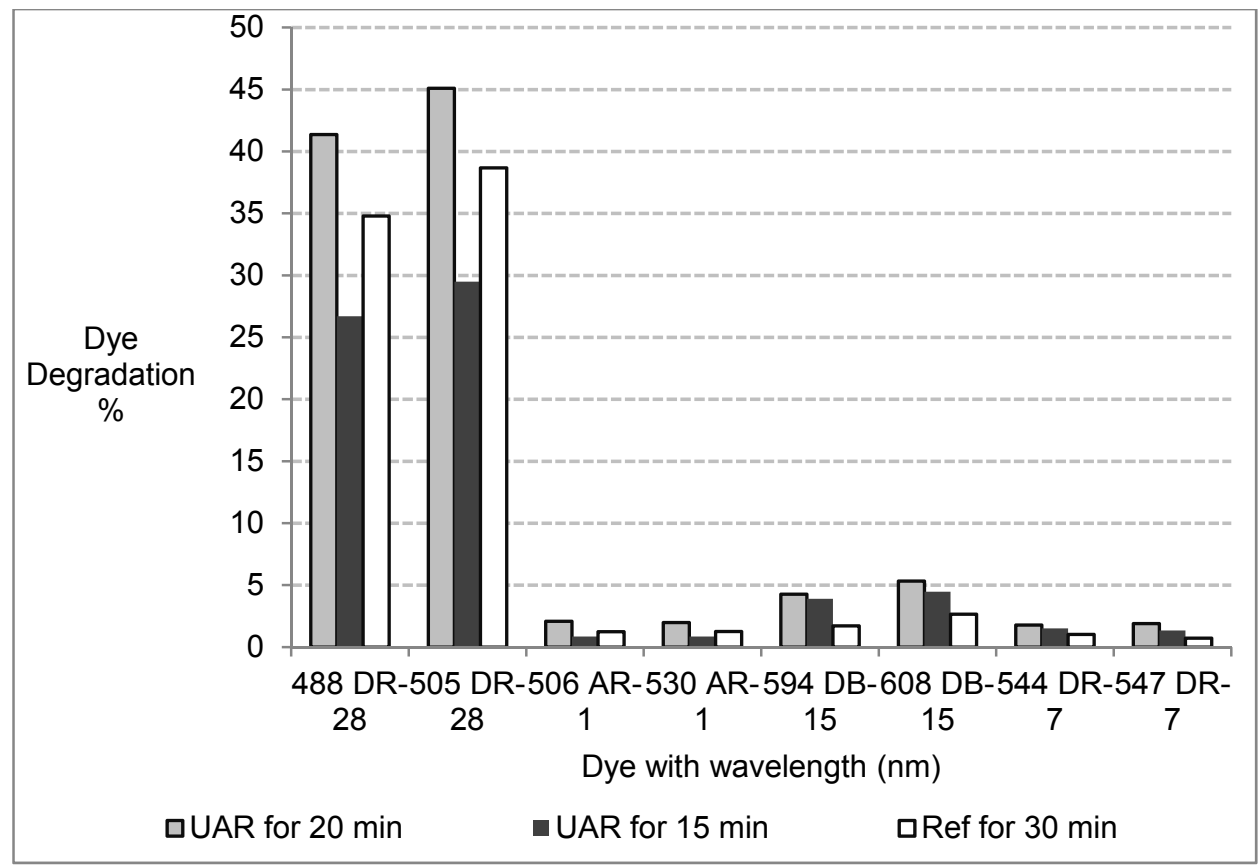

Figure 6. Comparative absorbance difference at selected wavelengths after dyes reduction at $70{ }^{\circ} \mathrm{C}$ between experimental method 2 and reference method

The findings of experimental method 2 were comparable to experimental method 1 for AR-1. Absorbance in the visible region shows slow and gradual reduction till 20 min of UAR. Considering the results of AR1 at 506 and $530 \mathrm{~nm}$ (Figure 6), $20 \mathrm{~min}$ of UAR is better than reference reduction whereas $15 \mathrm{~min}$ is not comparable to the reference method.

The results of DB-15 (Figure 5 and 6 ) are also interesting with the key wavelengths (580, 594 and $608 \mathrm{~nm}$ ) in the visible region, favoring the UAR method. The trend of dye cleavage is in the order UAR at 20 min > UAR at 15 min > reference method. 
Results of DR-7 (Figure 5) are also in agreement with other dyes with slow and gradual degradation till 20 min of UAR. The effectiveness of UAR at 544 and $547 \mathrm{~nm}$ is in the same order as in the case of DB-15, however with comparatively lower dye degradation (Figure 6). DR-7 is the most stable dye among the dyes studied, showing only $1.57 \%$ average degradation by reference method.

The most prominent absorbance changes were observed in the case of DR-28 (Figure 5) showing 36.7\% degradation by the reference method. Results of DR-28 obtained from experimental method 1 and 2 are in good agreement. In experimental method 1, 10 min of UAR was not enough to cause a reduction equivalent to the reference method even at $70^{\circ} \mathrm{C}$. But, in method 2 , it took almost $20 \mathrm{~min}$ of UAR for the dye to achieve a higher level of reduction than the reference method (Figure 6). The dye is reduced to a significant level and the change in absorbance is gradual and almost linear at 488 and $505 \mathrm{~nm}$. On comparing the results of DR-28 (Figure 6) in UAR with reference method, it is quite evident that the ultrasound energy has caused the reaction to complete in lesser time. This could be attributed to the cumulative amount of energy transmitted through ultrasound and conventional heating which is probably higher than the conventional heating alone.

\section{Effect of ultrasound on reduction through modified standard method (experimental method 3)}

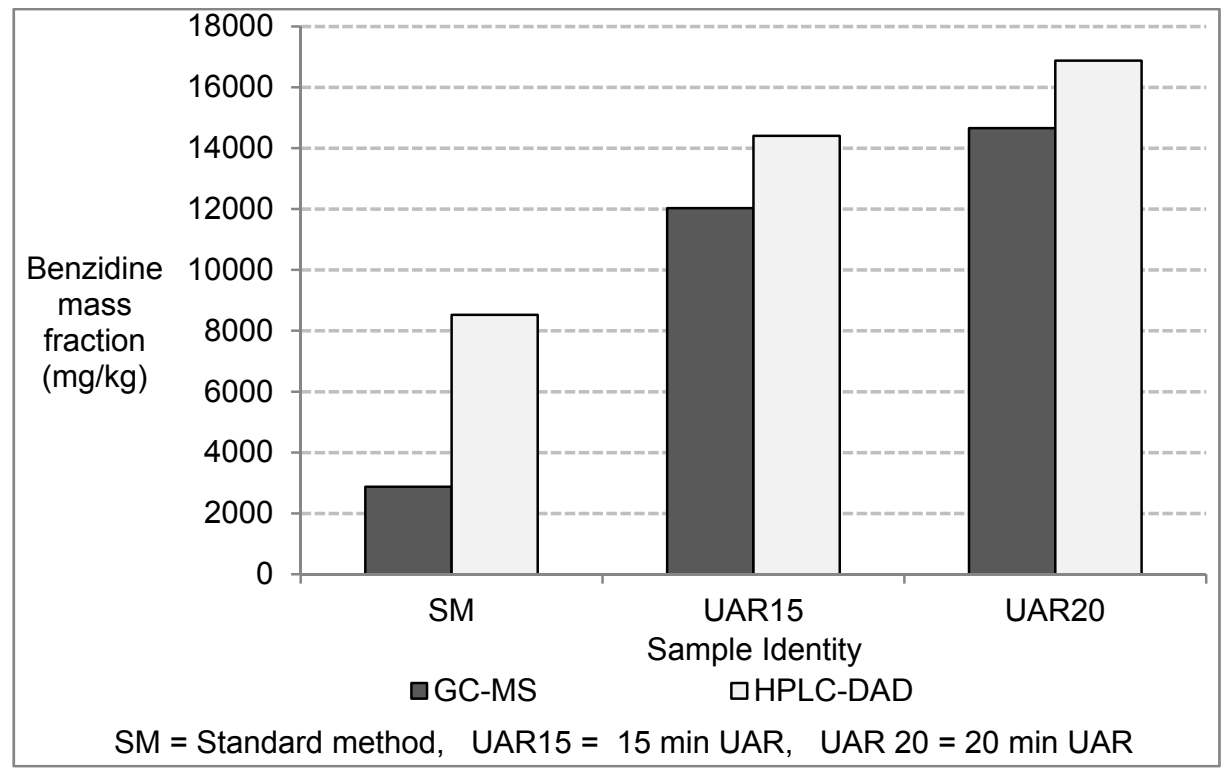

Figure 7. Comparative benzidine profile of standard method reduction and UAR for DR-28 dye 
Results of experimental method 1 and 2 obtained through UV-visible spectroscopy proved very helpful in designing experimental method 3 and were also confirmed by experimental method 3. For this purpose, DR-28 dye was selected as it showed highest degradation among the selected dyes. The mass fraction $(\mathrm{mg} / \mathrm{kg}$ ) of benzidine (biphenyl-4,4'-diamine) directly indicates the reduction of DR-28 dye in Figure 7.

Results from GC-MS and HPLC-DAD are in good agreement however results obtained from HPLC in general are slightly higher. But the general trend through both the techniques is same. Previous results obtained from UV-visible spectroscopy were further confirmed by GC-MS and HPLC-DAD showing that 15 min of UAR through experimental method 3 caused greater degradation of DR-28 as compared to the standard test method for azo colorants [11]. The degradation after 20 min of UAR was even higher. Chromatograms obtained from GC-MS and HPLC-DAD are shown in Figure 8.

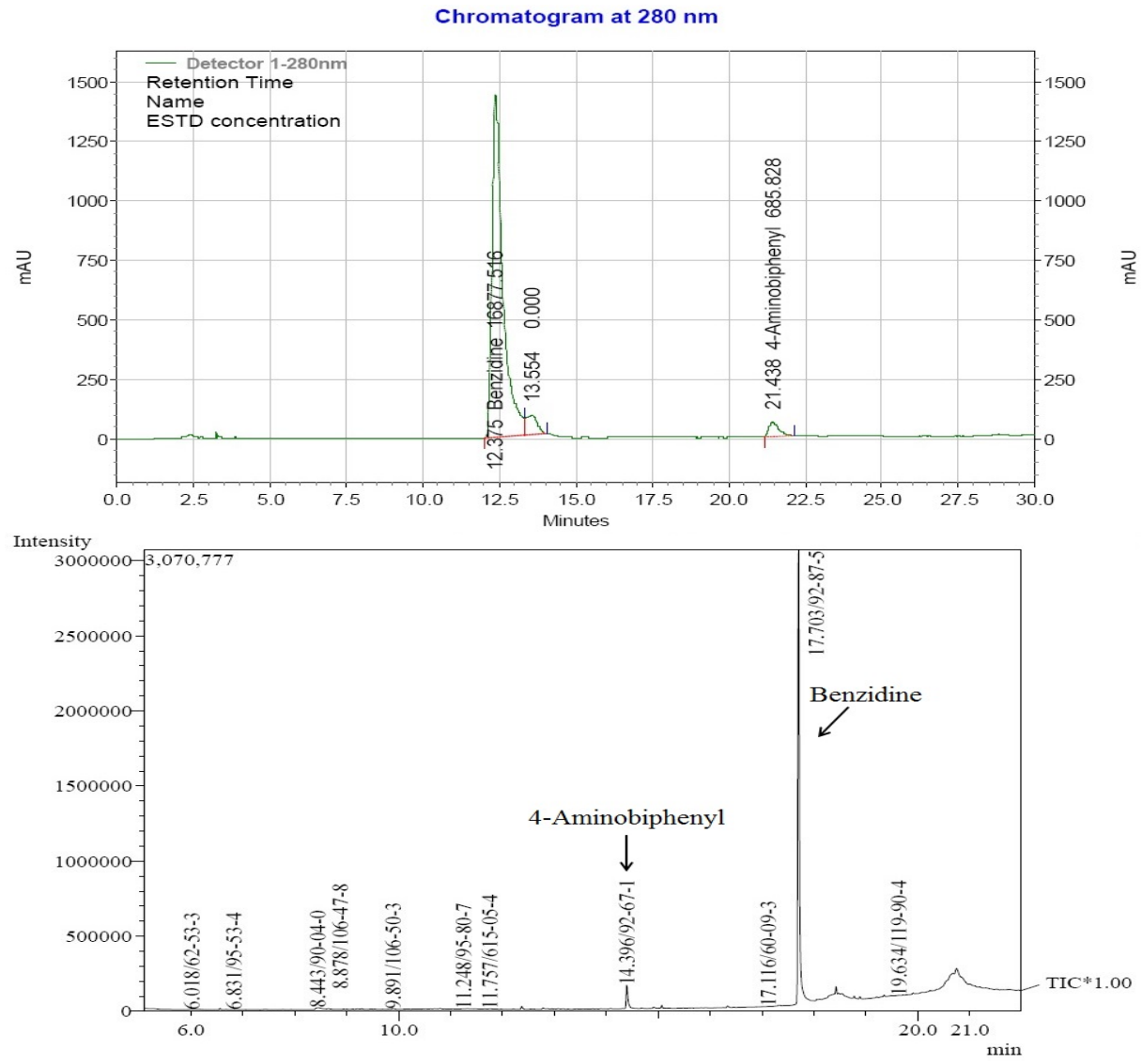

Figure 8. Chromatograms of DR-28 dye subjected to UAR for $20 \mathrm{~min}$, Above: HPLC-DAD (at $280 \mathrm{~nm}$ ), Below: GC-MS 
The effect of ultrasound is profound at $70{ }^{\circ} \mathrm{C}$ causing a reduction in reaction time of approximately $42 \%$. There are several factors that contribute to the reduction of dyes. It has been established that an overall low molecular weight, sterically less hindered diazo bonds and structural simplicity promote dye decolonization. However, the trend of ease of reduction is not exclusively based on these factors. Other factors such as high pKa values, less number of $\mathrm{SO}_{3}{ }^{-}$groups, and preference of hydrazone epimer over the azo epimer (dye) also make the dye susceptible towards ultrasound degradation [40, 4648]. It should also be mentioned here that UAR methods are more suitable for solvent soluble azo dyes and are likely to yield shorter reduction times because water soluble dyes containing highly polar groups are less likely to get into the gas liquid interface produced during sonication and therefore are not directly exposed to the high temperature and pressure conditions [40, 49]. Longer durations of UAR were not trialed because these would not support the hypothesis of time effectiveness as compared to standard method.

It is usually easy to reduce a dye powder as compared to a dye present in a matrix (leather, textile etc.). The main reason could be the interaction of the reducing agent with the matrix components. Besides, the reducing agent would have to penetrate the sample matrix to reach the active sites (azo chromophores) present on the dye molecule. However, ultrasonication would enhance the penetration of the reducing agent into the matrix. It is quite evident that the dyes which are reduced to a significant level by the reference method are also responding well to UAR. Therefore, it may be inferred that the percent reduction, using modified method may be useful in predicting the fate of a dyed product in terms of acceptance or rejection for export.

\section{CONCLUSIONS}

Ultrasound is a greener and environmental friendly technique. Ultrasound assisted reduction has the potential to reduce studied dyes in shorter time. All dyes showed good response to UAR, proportional to reaction temperature as analyzed by UV-visible spectroscopy. The results of experimental method 1 showed that AR-1 and DB-15 achieved reductions through UAR, higher than the reference method within ten min of time at $60{ }^{\circ} \mathrm{C}$ whereas DR-7 achieved at $70{ }^{\circ} \mathrm{C}$. However, degradation of DR-28 in ten min of UAR was not comparable to the reference method, even at $70^{\circ} \mathrm{C}$. According to experimental method 2, DB-15 and DR-7 achieved reductions equivalent to the reference method in $15 \mathrm{~min}$ of UAR at $70{ }^{\circ} \mathrm{C}$ whereas AR-1 and DR-28 achieved in 20 min of UAR. 
According to the results of experimental method 3 obtained through GC-MS and HPLC-DAD for DR-28 dye, even 15 min of UAR caused a greater reduction as compared to the standard method (BS EN 14362-1, F) for colorants. Results of 20 min of UAR are even better in terms of dye degradation. The results from GC-MS and HPLC-DAD are comparatively more reliable as compared to the results of UV-visible spectroscopy. Energy saving in UAR would be $\sim 85 \%$ as compared to standard method of reduction for colorants. Similarly, the time saving in case of UAR would be around $42 \%$ i.e. $25 \mathrm{~min}$ per analysis. Results suggest that these figures could be improved further if similar data is collected for more azo dyes.

The screening of azo dyes for their ability to release potentially harmful aromatic amines is routinely carried out in labs around the world for existing and new dyes. The proposed greener approach for standard method of reduction will allow the test to be carried out in comparatively shorter time, with parallel saving of energy.

\section{EXPERIMENTAL SECTION}

Reagent grade sodium dithionite (>87\%), extra pure tin (II) chloride dihydrate and silica gel 60 (70-230 mesh ASTM) were obtained from Merck (Germany). Tertiary butyl methyl ether solvent (reagent grade) was acquired from Fisher scientific, UK. Four dyes; AR-1, DR-15, DR-28 and DR-7 were obtained from local market in Karachi, Pakistan. Citric acid powder (general purpose reagent grade) and hydrochloric acid (AR grade, 37\%) were purchased from $\mathrm{BDH}$ Ltd. (England) whereas sodium hydroxide (AR grade) was procured from Riedel-deHaën (Germany).

Stock solutions using $0.106,0.115,0.109$, and $0.140 \mathrm{~g}$ of DR-28, AR$1, \mathrm{DB}-15$, and DR-7, respectively, were prepared in $500 \mathrm{ml}$ of distilled water. The UV-Visible scans for DB-15, AR-1, DR-7, and DR-28 dyes were recorded with dilutions of $2.3,4.3,2.3$, and $3.7, \mathrm{mg} / 100 \mathrm{ml}$, respectively. Citrate buffer $(\mathrm{pH}=6.0)$ was prepared using citric acid and sodium hydroxide solution [50].

\section{Reference method}

The reaction mixtures were prepared by pipetting appropriate volumes (to get the dye concentrations stated in Table 2) from the stock solutions into the reaction vessel. Total volumes were made upto17 $\mathrm{ml}$ by adding $0.03 \mathrm{M}$ citrate buffer as solvent with the help of graduated pipettes. The reaction was initiated in a $50 \mathrm{ml}$ round bottomed flask (Pyrex) by the addition of $3 \mathrm{ml}$ of 
freshly prepared dithionite solution containing $0.12 \mathrm{~g}$ of sodium dithionite. Reduction step was kept mild, analogous to the standard method for colorants (BS EN 14362-1:2012, F). Reference reactions were performed in a thermostatic water bath (Memmert, Germany) at $70{ }^{\circ} \mathrm{C}$, for 30 min and then cooled down immediately to $\sim 10^{\circ} \mathrm{C}$ in ice cooled water bath. The absorbance measurements were taken on a Nicolet Evolution 100, double beam spectrophotometer from Thermo Electron Corporation (USA) using standard quartz cuvettes.

\section{Reference method modified with ultrasound assisted reduction at different temperatures (Experimental method 1)}

The dye concentrations used for reduction in experimental method 1 are 2.3, 2.2, 2.8 and $4.2 \mathrm{mg} / 100 \mathrm{ml}$ for AR-1, DB-15, DR-7 and DR-28 respectively. For other experimental conditions refer to Table 2 . Ultrasound assisted reductions were carried out in a $135 \mathrm{~W}$, temperature controlled, Ultrasonic bath, Labsonic, LBS2-4,5, Italy, equipped with digital timer, having internal dimensions of $300 \times 150 \times 100 \mathrm{~mm}$ ( $4.5 \mathrm{~L}$ capacity), with an operational frequency of $40 \mathrm{kHz}$ and temperature range of 20 to $80^{\circ} \mathrm{C}$.

The sample vessel was adjusted in the center of the sonicator at the same depth and water level in all the experiments to minimize exposure variations. The reactions were carried out at different temperatures for $10 \mathrm{~min}$.

\section{Reference method modified with ultrasound assisted reduction at fixed temperature (Experimental method 2)}

The dye concentrations used for reduction in experimental method 2 are 3.2, 5.5, 7.8 and $5.1 \mathrm{mg} / 100 \mathrm{ml}$ for AR-1, DB-15, DR-7 and DR-28 respectively. For other experimental conditions refer to Table 2. These experiments were conducted in recommended polytetrafluoroethylene (PTFE) vessels for 5 , 10 , and $15 \mathrm{~min}$. Reaction mixtures were maintained at $70 \pm 1^{\circ} \mathrm{C}$ by placing these in preheated water bath at $77^{\circ} \mathrm{C}$ for 20 min prior to sodium dithionite addition. The temperature-time correlations were obtained from a separate set of experiments presented in Figure 9.

The concentrations of dyes were then raised to get maximum sensitivity as shown in Table 2. Reference reactions were repeated and validated in these PTFE vessels. To confirm the findings of experimental method 1 and 2, DR-28 was tested with standard test method EN 14362-1:2012 [11] and experimental method 3 . 


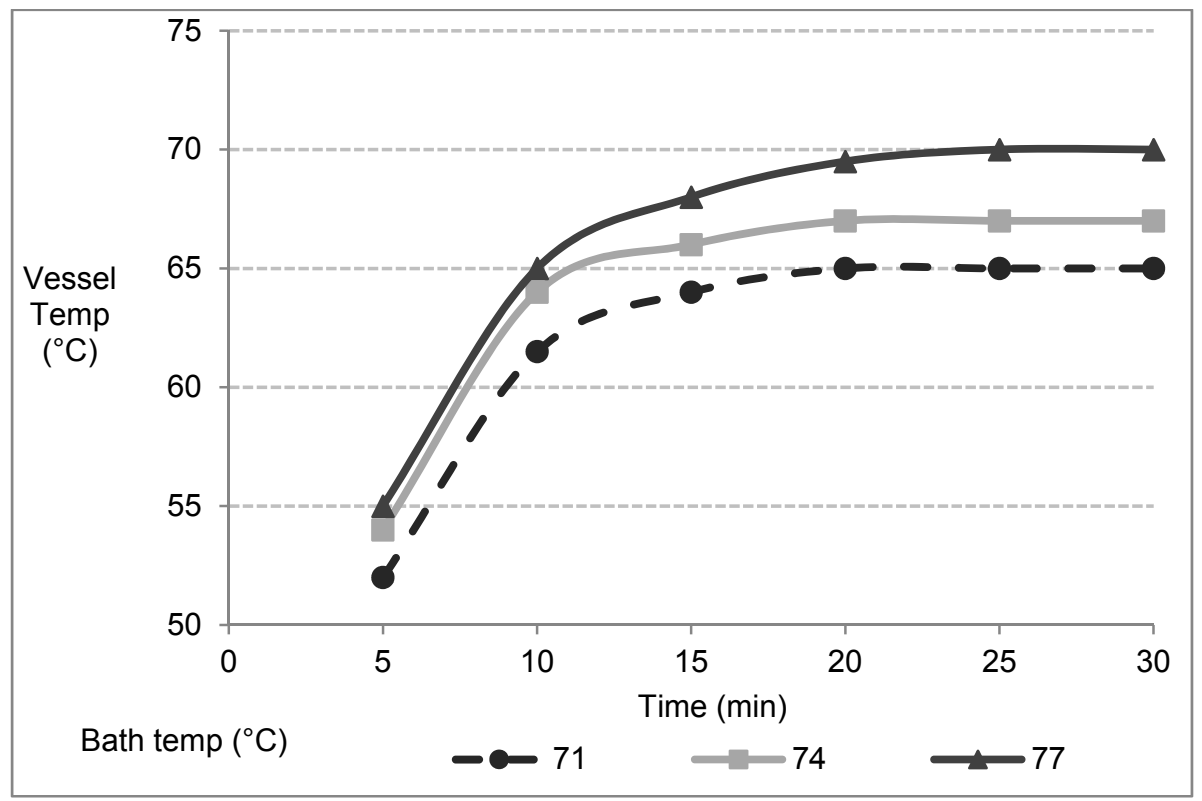

Figure 9. Relation between water bath and Teflon vessel content temperatures

\section{Standard method BS EN 14362-1:2012 (annex F)}

Direct red 28 dye was analyzed by standard method for determination of certain aromatic amines in colorants, BS EN 14362-1:2012 (F), [11]. The final extract solutions were subjected to instrumental analysis by GC-MS and reconfirmed using HPLC-DAD.

Gas chromatographic analyses were carried out on GC-2010 from Shimadzu, Japan equipped with AOC-20i+s auto sampler/injector assembly linked with a computer through GC-MS Real time analysis software. The instrument was coupled with a mass spectrometer detector, QP2010. GC column, DB-35MS $(25.0 \mathrm{~m} \times 0.20 \mathrm{~mm}, 0.33 \mu \mathrm{m} \mathrm{df})$ specific for aromatic amines was used. The 26 aromatic amine standards were obtained from Dr. Ehrenstorfer Quality (EQ) $\mathrm{GmbH}$, Germany. Separate stock solutions containing 2000 ppm of each amine were prepared, followed by working solution mixtures of all standards having $200 \mathrm{ppm}$ of each amine. 1, 5, 15 and 30 ppm dilutions were prepared for calibration of GC-MS method.

All standards and samples were injected in 'Split' mode with a split ratio of $1: 10$. The temperature program was set as follows; initial temperature $60{ }^{\circ} \mathrm{C}$ was held for $1 \mathrm{~min}$, ramped at $14{ }^{\circ} \mathrm{C} / \mathrm{min}$ to $320^{\circ} \mathrm{C}$ and finally hold for 
5 min. Total run time was $\sim 25 \mathrm{~min}$. Acquisition was carried out in SIM mode for better detection limit. Target ion $\mathrm{m} / \mathrm{z}$ was 184 for benzidine, with first and second qualifier ions at $\mathrm{m} / \mathrm{z} 185$ and 156 respectively for confirmation.

A HPLC system (LabAlliance, 2500 Plus, USA) with quaternary pumps and diode array detector (LabAlliance, UV6000LP, USA) assisted by a computer through EZchrome Elite software was used. HPLC column was reverse phase Spherisorb ${ }^{\circledR}, 5.0 \mu \mathrm{m}$, ODS1 from Waters, having dimensions $4.0 \times 250 \mathrm{~mm}$. A linear gradient method for leather was optimized for eight aromatic amines. A $10 \mu \mathrm{L}$ sample loop was used. Three chromatograms were recorded at 240, 280 and $305 \mathrm{~nm}$. Column oven temperature was set at $40{ }^{\circ} \mathrm{C}$. Eluent 1 was modified to $30 \%$ acetonitrile in methanol and eluent 2 was phosphate buffer ( $\mathrm{pH} 6.9)$. The gradient started with $25 \%$ eluent 1 , increasing linearly to $80 \%$ within $30 \mathrm{~min}$. The total solvent flow rate was adjusted to 0.65 $\mathrm{ml} / \mathrm{min}$. A three-point calibration was carried out with standard amine mixture containing 2, 20 and $40 \mathrm{ppm}$ of eight selected amines. $\lambda_{\max }$ used for the confirmation of benzidine was $278 \mathrm{~nm}$.

\section{Standard method (EN 14362-1) modified with ultrasound assisted reduction (Experimental method 3)}

The standard method for determination of certain aromatic amines in colorants, EN 14362-1:2012 (F), [11] was repeated for DR-28, modified by replacing standard reduction with ultrasound assisted reduction. Heating during reduction was accompanied by ultrasonic waves for the desired durations. Experimental method 3 was performed with two different UAR durations i.e. $15 \mathrm{~min}$ and $20 \mathrm{~min}$. Rest of the procedure, parameters and reagent quantities were same as mentioned in standard method (EN 143621). Final extracts were analyzed by GC-MS and HPLC-DAD with the same instrumental conditions and configurations mentioned in the standard method above.

\section{ACKNOWLEDGMENTS}

The authors are grateful to Dr. Hafiz Rab Nawaz, Director Leather Research Center, PCSIR, for co-operation and support throughout the work. 


\section{REFERENCES}

1. M. J. Prival, S. J. Bell, V. D. Mitchell, M. D. Peiperl, V. L. Vaughan, Mutation Research/Genetic Toxicology, 1984, 136, 33-47.

2. F. Calogero, H. S. Freeman, J. F. Esancy, W. M. Whaley, B. J. Dabney, Dyes and Pigments, 1987, 8, 431-447.

3. M. Kojima, M. Degawa, Y. Hashimoto, M. Tada, Biochemical and biophysical research communications, 1991, 179, 817.

4. C. P. Hartman, G. E. Fulk, A. Andrews, Mutation Research/Genetic Toxicology, 1978, 58, 125.

5. E. Messerly, J. Fekete, D. Wade, J. Sinsheimer, Environmental and molecular mutagenesis, 1987, 10, 263.

6. H. S. Freeman, J. F. Esancy, L. D. Claxton, Chemtech, 1991, 21, 438.

7. Y. Hashimoto, H. Watanabe, M. Degawa, Gann= Gan, 1981, 72, 921.

8. B. de Campos Ventura-Camargo, M. A. Marin-Morales, Textiles and Light Industrial Science and Technology, 2013, 2, 85-103.

9. G. de Aragao Umbuzeiro, H. S. Freeman, S. H. Warren, D. P. De Oliveira, Y. Terao, T. Watanabe, L. D. Claxton, Chemosphere, 2005, 60, 55-64.

10. Environment Canada/Health Canada. "Aromatic Azo- and Benzidine-based substances", Screening assessment report, 2012, pp. 3-6.

11. BSI. Colorants - Methods for determination of certain aromatic amines. BS EN 14362-1, E (Annex F). The British Standards Institution, 2012.

12. ISO. Chemical tests for the determination of certain azo colorants in dyed leathers. ISO/DIS 17234-1/IUC 20-1. International organization for standards, 2012.

13. BSI. Textiles - Methods for determination of certain aromatic amines derived from azo colorants. BS EN 14362-1, E. The British Standards Institution, 2012.

14. R. D. Voyksner, R. Straub, J. T. Keever, H. S. Freeman, H. Whei-Neen, Environmental science \& technology, 1993, 27, 1665-1672.

15. A. Puntener, D. Mausezahl, C. Page, Journal of the Society of Leather Technologists and Chemists, 1993, 77, 1.

16. A. G. Pindar, H. M. Tinsley, Analyst, 1984, 109, 1101-1102.

17. R. F. Straub, R. D. Voyksner, J. T. Keever, Analytical Chemistry, 1993, 65, 2131-2136.

18. D. Muralidharan, V. S. Rao, Journal of the Society of Leather Technologists and Chemists, 1994, 78, 139-41.

19. F. Planelles, E. Verdu, D. Campello, N. Grane, J. Santiago, Journal of the Society of Leather Technologists and Chemists, 1998, 82, 45-52.

20. M. C. Garrigós, F. Reche, M. L. Marin, A. Jiménez, Journal of Chromatography A, 2002, 976, 309-317.

21. M. Mościpan, M. Zarębska, R. Kulesza, Chemik, 2016, 70, 135-143.

22. F. Parolin, U. M. Nascimento, E. B. Azevedo, Environmental technology, 2013, 34, 1247-1253.

23. G. Tezcanli-Güyer, N. H. Ince, I. A. Alaton, Coloration technology, 2003, 119, 292-296. 
RAPID ULTRASOUND ASSISTED REDUCTION OF AZO DYES FOR SCREENING BANNED ...

24. G. Tezcanli-Guyer, N. H. Ince, Ultrasonics Sonochemistry, 2003, 10, 235-240.

25. A. S. Özen, V. Aviyente, G. Tezcanli-Güyer, N. H. Ince, The Journal of Physical Chemistry A, 2005, 109, 3506-3516.

26. L. H. Keith, L. U. Gron, J. L. Young, Chemical reviews, 2007, 107, 2695-2708.

27. M. de la Guardia, S. Garrigues, "Handbook of green analytical chemistry"., Wiley Online Library, 2012, chapter 7, pp. 117.

28. A. S. Özen, V. Aviyente, G. Tezcanli-Güyer and N. H. Ince, The Journal of Physical Chemistry A, 2005, 109, 3506-3516.

29. M. Işık, D. T. Sponza, Journal of International Environmental Application \& Science, 2006, 1, 1-26.

30. G. C. Santos, C. R. Corso, Water, Air, \& Soil Pollution, 2014, 225, 2026.

31. P. Suwannawong, S. Khammuang, R. Sarnthima, Journal of Biochemical Technology, 2010, 2, 182-186.

32. W. Hailei, L. Ping, L. Guosheng, L. Xin, Y. Jianming, Enzyme and Microbial Technology, 2010, 47, 37-43.

33. C. I. Pearce, R. Christie, C. Boothman, H. von Canstein, J. T. Guthrie, J. R. Lloyd, Biotechnology and bioengineering, 2006, 95, 692-703.

34. A. Assadi, R. Nateghi, G. R. Bonyadinejad, M. M. Amin, International Journal of Environmental Health Engineering, 2012, 1, 1-5.

35. I. Gültekin, G. Tezcanli-Güyer, N. H. Ince, Ultrasonics sonochemistry, 2009, 16, 577-581.

36. N. H. Ince, G. Tezcanlí, Dyes and Pigments, 2001, 49, 145-153.

37. Z. Eren, N. H. Ince, F. N. Acar, Journal of Advanced Oxidation Technologies, 2010, 13, 206-211.

38. G. Tezcanli-Güyer, N. H. Ince, Ultrasonics, 2004, 42, 603-609.

39. M. Q. Cai, X. Q. Wei, Z. J. Song, M. C. Jin, Ultrasonics sonochemistry, 2015, 22, 167-173.

40. S. K. Sharma, "Green Chemistry for dyes removal from waste water: research trends and applications”., John Wiley \& Sons, 2015.

41. L.-H. Ahlström, C. S. Eskilsson, E. Björklund, Trends in Analytical Chemistry, 2005, 24, 49-56.

42. M. Cai, M. Jin, L. K. Weavers, Ultrasonics sonochemistry, 2011, 18, 1068-1076.

43. B. P. Vellanki, B. Batchelor, A. Abdel-Wahab, Environmental engineering science, 2013, 30, 264-271.

44. A. H. Gemeay, Dyes and pigments, 2002, 54, 201-212.

45. M. de la Guardia, S. Garrigues, "Handbook of green analytical chemistry". 1st ed., John Wiley \& Sons, Pondicherry, 2012.

46. N. H. Ince, G. Tezcanli-Güyer, Ultrasonics, 2004, 42, 591-596.

47. A. S. Özen, V. Aviyente, R. A. Klein, The Journal of Physical Chemistry A, 2003, 107, 4898-4907.

48. J. Oakes, P. Gratton, Journal of the Chemical Society, Perkin Transactions 2, 1998, 1857-1864.

49. R. Singla, F. Grieser, M. Ashokkumar, Ultrasonics sonochemistry, 2009, 16, 28-34.

50. J. Mendham, R. Denney, J. Barnes, M. Thomas, "Vogel's Quantitative Chemical Analysis”, Pearson Education Ltd., Singapore, 2000, pp. 768-769. 